\title{
Gastrópodes Abissais do Plato Marginal de Pernambuco, Brasil - Atlântico Sul OCIDENTAl.
}

\author{
José CARLos NASCIMENTO DE BARROS ${ }^{(1)}$ \\ FRANKLIN NOEL DOS SANTOS ${ }^{(2)}$ \\ ISAÍRAS PEREIRA PADOVAN ${ }^{(3)}$ \\ 1 - Prof. Assistente do Museu de Malacologia/UFRPE \\ 2 - Mestrando em Oceanografia Biológica/UFPE \\ 3 - Prof. Adjunto do Departamento de Histologia da UFPE.
}

\begin{abstract}
The results of the taxonomic and ultra-estructural studies of abyssobentic mollusks obtained from different types of shifting substrates as calcareous mud and organogenic biodetritic sediments were dragged from off the Plateau of Pernambuco by the Oceanographic Vessel Almirante Câmara in 1976. The analysis of 15 specimens, turns possible the identification of 6 rare abyssal species of Gastropoda. Occurrence information of these species is added to the geographical distribution for the following coordinates and depths: Anatoma aedonia (Watson, 1886), Solariella actinophora Dall, 1890 and Brookula conica (Watson, 1885), to $08^{\circ} 25^{\prime} 01^{\prime \prime} \mathrm{S}, 34^{\circ} 19^{\prime} 01^{\prime \prime} \mathrm{W}$, at

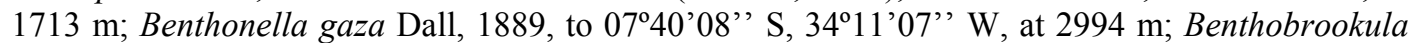
powelli and Benthobrookula lamont Clarck, 1961 to $08^{\circ} 25^{\prime} 15^{\prime \prime}$ ' S, $34^{\circ} 19^{\prime} 01^{\prime \prime} \mathrm{W}$, at $1713 \mathrm{~m}$.
\end{abstract}

\section{RESUMO}

Informam-se os resultados sobre o estudo taxonômico dos moluscos abissobênticos obtidos sobre diferentes tipos de substratos móveis: lama calcária, lama arenosa e sedimentos orgânicos biodetríticos (vasa de foraminíferos e cascalho de pterópodes), dragados do Platô de Pernambuco pelo Navio Oceanográfico Almirante Câmara em agosto de 1976. A triagem do material foi feita após o peneiramento dos sedimentos sob água corrente em "mesh tyler" de variadas dimensões de malha sendo as conchas identificadas sob microscópio eletrônico de varredura após metalização com ouro. A análise de 15 exemplares possibilitou o reconhecimento de seis espécies de gastrópodes muito raros ou ausentes de citação para o Brasil. Acrescenta-se a distribuição geográfica desconhecida a informação da ocorrência dessas espécies para as seguintes coordenadas e profundidades: Anatoma aedonia (Watson, 1886), Solariella actinophora Dall, 1890 e Brookula conica (Watson, 1885), em 08 $25^{\prime} 01^{\prime \prime}$ S, 34 $4^{\circ} 19^{\prime} 01^{\prime \prime}$ W, a 1713 metros; Benthonella gaza Dall,

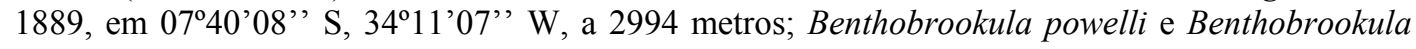
lamont Clarck, $1961 \mathrm{em} 08^{\circ} 25^{\prime} 15^{\prime \prime}$ S, $34^{\circ} 19^{\prime} 01^{\prime \prime} \mathrm{W}$, a 1713 metros. O material foi obtido com o apoio da Marinha do Brasil e do Laboratório de Geologia Marinha- LAGEMAR da Universidade Federal Fluminense.

\section{INTRODUÇÃo}

O quase total estado de esquecimento a que as grandes expedições oceanográficas brasileiras, tem relegado à exploração e pesquisa de mares profundos, a falta de trabalhos recentes que indiquem uma atualização no conhecimento da malacofauna da região bêntica oceânica e o

Tropical Oceanography, Recife, v. 29, n. 1, p. 59-66, 2001. 
escasso número de coleções representativas e confiáveis, são os principais fatores responsáveis pelo estado atual de conhecimento incipiente ao que tange a fauna malacólogica dos andares batial e abissal da costa brasileira.

As pesquisas oceânicas realizadas em várias partes do mundo, tem revelado um número significativo de novos taxa de animais macro e microscópicos pertencente a vários Filos, sobretudo o Mollusca.

Ekmam (1953), afirmou que para muitos grupos de moluscos abissais, com exceção das lulas, existiria ainda muito o que se listar, dada a ausência de pesquisas mais freqüentes sobre a vida do fundo oceânico.

De acordo com Clarke (1961) grande parte da fauna de moluscos abissais teria se originado de águas pouco profundas em todas as regiões do mundo e não apenas nas regiões polares como se acreditava. Embora muitos Gêneros e Famílias sejam cosmopolitas, alguns grupos de moluscos teriam invadido a zona abissal em era geológica recente, sendo confirmadas a algumas regiões, embora sejam adjacentes às áreas rasas dos quais foram derivados.

Bayer (1971), durante o ano de 1960, realizou uma série de expedições de pesquisas às águas próximas às Bahamas, Golfo de Honduras e na Costa Nordeste da América do Sul. Foram realizadas as primeiras dragagens de águas profundas ao largo daquelas áreas e descobriu-se um mundo malacológico inteiramente novo, muitas espécies novas para a Ciência, incluindo uma nova forma de Voluta Linnaeus (Cordilynia Bayer) e um gênero de Coralliophilidae até então assinalado apenas para o Japão, representado pelas espécies Babelomurex fax B. e Babelomurex sentix B.

Clarke Jr. (1961) estudou os moluscos abissais do Atlântico Sul coligidos em 1958, durante o $40^{\circ}$ cruzeiro do NOc. VEMA, o qual realizou expedição biológica e geológica da área

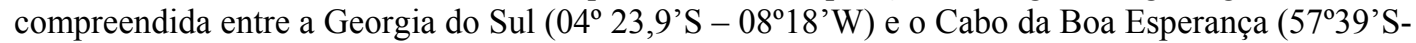
$\left.13^{\circ} 37^{\prime} \mathrm{W}\right)$. Das amostras obtidas oito foram de profundidades abissais, os numerosos moluscos coletados, demonstraram-se diferentes das formas encontradas no Atlântico Norte, sendo a maioria deles representadas por novas espécies.

Sobre os moluscos do Brasil ainda é mais reduzida a informação científica, podendo-se citar Watson (1886), Abbott (1974) e Rios (1994), que citam algumas espécies ocorrentes no Atlântico Sul.

Apresenta-se uma pequena lista de micromoluscos abissais pouco conhecidos e raros, com descrição inédita da ultraestrutura ausente nas coleções malacológicas do Brasil. Excluindo-se os Aclididae, cuja a revisão está em andamento.

\section{MAteriais E MÉTOdos}

O material utilizado neste estudo foi obtido através de dragagens em águas profundas, realizadas no Platô Marginal de Pernambuco pelo NOc. Almirante Câmara, em agosto de 1976, durante o Cruzeiro de Pesquisa Geológica aos Platôs do Nordeste Brasileiro.

O sedimento obtido foi peneirado sob água corrente, em peneiras geológicas de varias dimensões de malha $(0,295,0,5,0,68$ e 2,00 mm). As respectivas frações granulometricas foram secas em estufa à $60^{\circ} \mathrm{C}$, sendo acondicionadas em sacos plásticos.

O material conchífero foi triado sob estereomicroscópio Zeiss de até 40X de aumento, e identificado de acordo com Watson (1886), Abbott (1974), Clark Jr. (1961) e Rios (1985), sendo posteriormente, depositado na Coleção Malacológica do Departamento de Pesca da Universidade Federal Rural de Pernambuco.

Para o estudo ultraestrutural e sistemático, as conchas foram metalizadas em ouro "standard", analisadas e fotografadas em microscópio eletrônico de varredura Jeol-T-200, resultando na determinação específica dos grupos.

Tropical Oceanography, Recife, v. 29, n. 1, p. 59-66, 2001. 


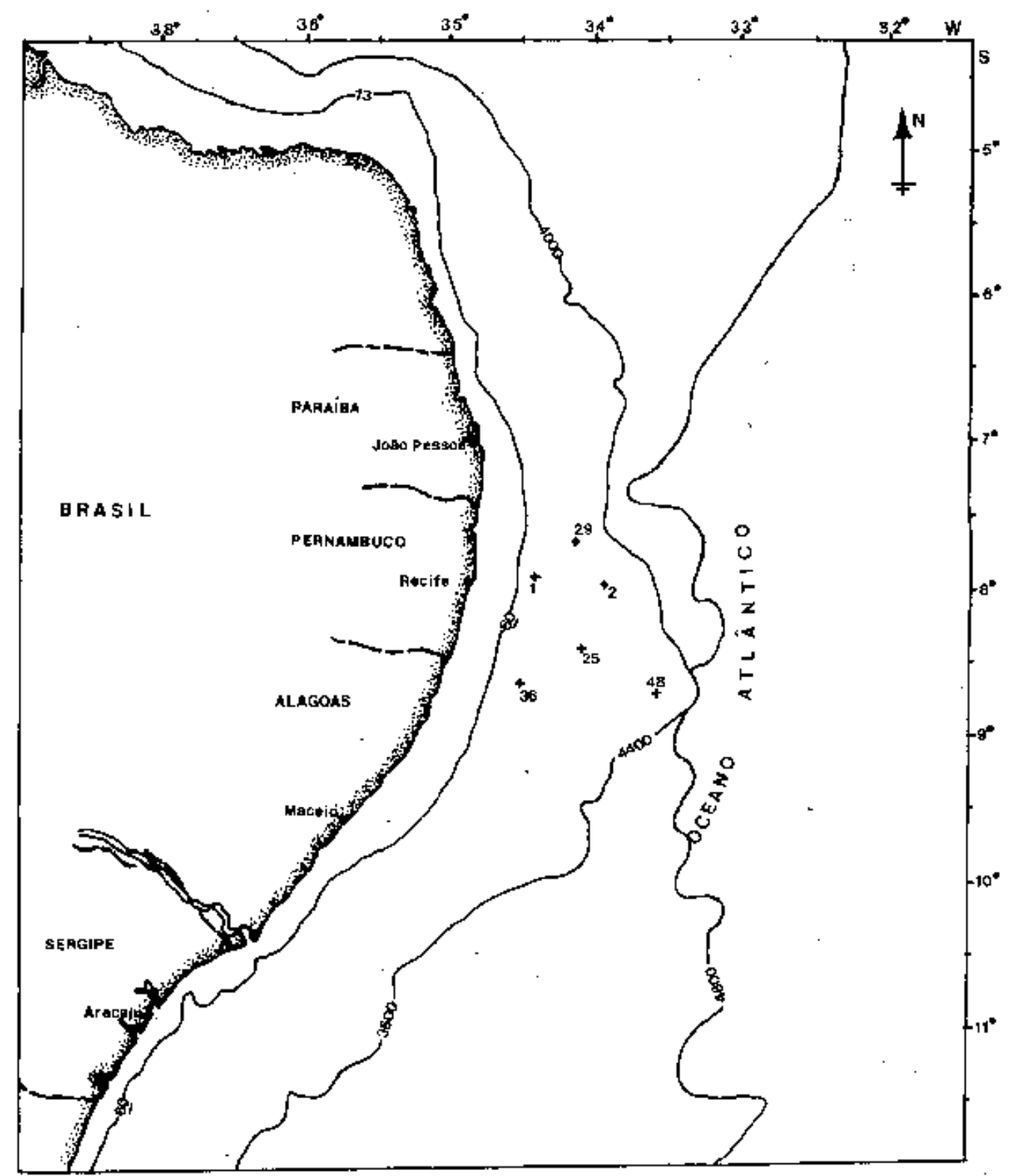

Figura 1- Mapa das estações de coleta no Platô Marginal de Pernambuco.

\section{ReSUltados E COMENTÁRIOS}

\section{CLASSE GASTROPODA}

SUBCLASSE PROSOBRACHIA

ORDEM ARCHAEOGASTROPODA

Superfamília Scissurellidae Gray, 1847:

Conchas microscópicas com poucas voltas e umbilicadas. Espiral turbinada ou comprimida. Lábio externo com um entalhe na periferia da volta, caracterizando uma selenizona.

Tropical Oceanography, Recife, v. 29, n. 1, p. 59-66, 2001. 
Gênero Anatoma Woodward, 1859

Conchas microscópicas turbinadas ou troquiformes carinadas. Espiral alta e cêntrica. Selenizona sobre metade superior das voltas. Entalhe geralmente aberto [= Schizotrochus Monterosato, 1877]. Antoma aedonia (Watson, 1886) (Figura 2a)

\begin{tabular}{llllll}
\hline Col. MMUFRPE & Local & Dragagem & $\begin{array}{l}\text { Comprimento } \\
\text { Mm }\end{array}$ & $\begin{array}{l}\text { Largura } \\
\text { Mm }\end{array}$ & Voltas \\
\hline 4562 & Platô/PE & D-22 & 0,8 & 1,0 & 4 \\
\hline
\end{tabular}

Material Examinado: 1 exemplar coletado em 06/08/76, dragagem 22; $08^{\circ} 25^{\prime} 01^{\prime}$ 'S , 34 $4^{\circ} 13^{\prime} 01^{\prime \prime}$ W, a 1713 metros de profundidade.

Diagnose: concha troquiforme de espiral larga e medianamente elevada de aspecto geral translúcido e de textura vítrea. Teleoconcha com voltas destrógiras de contorno arredondado, marcada pela selenizona que forma uma carina visível em todas as voltas. Superfície dos anfractos esculturadas por numerosas costelas oblíquas separadas por largos interespaços, sendo a porção suprasutural finamente reticulada e de interespaços lisos e a porção subsutural formada por uma ou duas linhas espirais fracas, localizadas entre as costelas. Sutura bem marcada pela porção posterior das costelas subsuturais oblíquas. Costelas fortemente opistóclinas e convexas. Abertura grande, circular, com lábio externo fino e fendido na sua porção mediana. A columela é curva e lisa, sendo a região parietal delgada e fortemente refletida sobre o umbílico. Base fortemente perfurada com um umbílico largo e profundo, ornamentadas em retículo por costelas e linhas axiais microscópicas. Protoconcha lisa, inflada e inclinada, submersa no topo da espiral. Núcleo liso e globoso.

Superfamília Cocculinoidea Thiele, 1909

Família Cocculinidae Dall, 1889

Conchas microscópicas e finas em forma de chapéu de cogumelo. Ápex sinistrógiro. Escultura radial e concêntrica. Cicatriz muscular interna em forma de ferradura.

Gênero Cocculina Dall, 1882

Conchas microscópicas cônicas elevadas, ápex sinistrógiro normalmente posicionado na porção anterior da columela.

Cocculina aff. rathbuni Dall, 1882 (figura 2b)

\begin{tabular}{llllll}
\hline \multirow{2}{*}{ Col. MMUFRPE } & \multirow{2}{*}{ Local } & \multirow{2}{*}{ Dragagem } & $\begin{array}{l}\text { Comprimento } \\
\mathrm{mm}\end{array}$ & $\begin{array}{l}\text { Largura } \\
\mathrm{mm}\end{array}$ & \multirow{2}{*}{ Voltas } \\
\hline \multirow{2}{*}{4563} & \multirow{3}{*}{ Platô/PE } & \multirow{2}{*}{$\mathrm{D}-20$} & 1,40 & 0,60 & --- \\
& & & 1,00 & 0,40 & --- \\
\hline
\end{tabular}

Material examinado: 3 exemplares coletados em 05/08/76, dragagem 20; 07040'08' 'S, 34 $11^{\circ}$ '07' 'W, a 2994 metros de profundidade.

Diagnose: Concha microscópica cônica-elevada, comprimida lateralmente e de aspecto vítreo. Teleoconcha não espiralada, em forma de chapéu ornamentada por linhas de crescimento concêntricas relativamente contínuas. Escultura radial inconspícua. Porção dorsal normalmente lisa e sem a presença de ápex. Borda ventral fortemente delgada e fracamente refletida. Eixo axial assimétrico, deslocado para a porção anterior da concha, a qual é curta e levemente convexa. A porção posterior é maior e de declividade mais suave que a porção anterior. O interior da abertura é inteiramente liso exceto pela presença de uma cicatriz muscular interna interrompida posteriormente.

Superfamília Trochoidea Rafinesque, 1815

Família Skeneidae Thiele, 1929

Tropical Oceanography, Recife, v. 29, n. 1, p. 59-66, 2001. 
Conchas pequenas a microscópicas de espiral variável e esculturada axial e espiralmente, raramente lisa, abertura circular. Entalhe umbilical presente.

Gênero Brookula Iredale, 1912

Conchas pequenas de formato globoso-turbinado, frágil, com voltas amplamente convexas e escultura predominantemente axial. Abertura arredondada.

Brookula conica (Watson, 1885) (figura 2c)

\begin{tabular}{llllll}
\hline \multirow{2}{*}{ Col. MMUFRPE } & \multirow{2}{*}{ Local } & \multirow{2}{*}{ Dragagem } & $\begin{array}{l}\text { Comprimento } \\
\mathrm{mm}\end{array}$ & $\begin{array}{l}\text { Largura } \\
\mathrm{mm}\end{array}$ & Voltas \\
\hline \multirow{4}{*}{4564} & & 1,00 & 0,97 & 4,0 \\
& & & 1,00 & 0,96 & 4,0 \\
& \multirow{3}{*}{ Platô/PE } & \multirow{2}{*}{$\mathrm{D}-22$} & 0,98 & 0,94 & 4,0 \\
& & & 0,97 & 0,86 & 3,5 \\
& & & 1,00 & 0,95 & 4,0 \\
\hline
\end{tabular}

Material examinado: 3 exemplares coletados em 06/08/76, dragagem 22; $08^{\circ} 25^{\prime} 01^{\prime}$ 'S, 34 19 '01' 'W, a 1713 metros de profundidade.

Diagnose: Concha microscópica de formação globoso turbinado de espiral medianamente elevada, de aspecto não translúcido. Teleoconcha com quatro voltas destrógiras fortemente convexas, marcadas por fortes costelas coincidentes ao longo de todas as voltas. Superfície dos anfractos esculturada por numerosas costelas axiais, separados por largos interespaços lisos. A volta do corpo é ornamentada por quinze a vinte costelas axiais fortes que descem até a base e terminam em uma grande fenda umbilical. Ornamentação espiral inconspícua. A sutura é profunda reentrante como em Epitonium S.S. Berry, 1910, sendo marcada pelas porções supra e subsuturais das costelas axiais relativamente ortóclimas. Abertura grandemente arredondada, sendo o lábio externo correspondente a última costela axial da margem anterior da volta do corpo. O interior deste lábio é liso e polido sem a presença de denticulações e a superfície normalmente afilada, se reflete em pequeno grau para região dorsal do anfracto. Lábio interno forte e grandemente côncavo. O callus parietal é tão forte quanto o lábio externo, o que oferece um aspecto de holóstoma à região oral. Base perfurada e profundamente umbilicada, ornada pelas terminações das costelas axiais da última volta. Protoconcha bem visível, globosa com ornamentação inconspícua e sem limite terminal evidenciado. Núcleo liso e visível no topo do ápex, melhor observado na face dorsal da concha.

Gênero Benthobrookula Clark, 1961

Conchas pequenas e umbilicadas, esculturadas por costelas axiais aproximadamente verticais e linhas ou costelas espirais se estendendo até a margem da abertura. Benthobrookula powelli Clark, 1961 (figura 2d)

\begin{tabular}{lllllc}
\hline Col. MMUFRPE & Local & Dragagem & $\begin{array}{l}\text { Comprimento } \\
\mathrm{mm}\end{array}$ & $\begin{array}{l}\text { Largura } \\
\mathrm{Mm}\end{array}$ & Voltas \\
\hline 4565 & Platô/PE & D-22 & 0,82 & 1,7 & 2,5 \\
\hline
\end{tabular}

Material examinado: 1 exemplar coletado em 06/08/76, dragagem 22; $08^{\circ} 25^{\prime} 01^{\prime \prime}$ S, 34 $4^{\circ} 19^{\prime} 01^{\prime \prime} \mathrm{W}$, a 1713 metros de profundidade.

Diagnose: concha microscópica translúcida, troquiforme, e profundamente umbilicada. Espiral baixa, fortemente comprimida. Teleoconcha com 2,5 voltas destrógiras convexas, ricamente esculturadas, separadas por uma sutura profunda que forma um canal espiral bem marcado. A escultura consiste de numerosas costelas axiais fortes e estreitas, que podem atingir até quarenta e cinco sobre a volta do corpo, inumeráveis linhas axiais microscópicas de crescimento são encontradas nos espaços intercostelares. A escultura espiral é formada por três cordas espirais conspícuas que cruzam as costelas axiais dando um aspecto fortemente reticulado. As cordas

Tropical Oceanography, Recife, v. 29, n. 1, p. 59-66, 2001. 
espirais nunca se aproximam em tamanho ao das costelas axiais. A base é larga e perfurada, sendo ornamentadas por linhas finas e quatro cordas que margeiam o umbílico. As quatro cordas ao redor do umbílico são aproximadamente do mesmo tamanho que as costelas axiais. A abertura é ovalada, com uma angulação posterior, os lábios externo e interno são fracamente marcados, porém callus e a região parietal podem estar fortemente refletidos sobre a base, sendo a columela muito curta e o lábio externo fortemente côncavo. Perístoma conspícuo. Umbílico largo e profundo. Protoconcha bubosa, plana, lisa, com terminalização inconspícua, exceto pelo surgimento da primeira costela axial da teleoconcha. Núcleo pouco evidente e submergido no ápex.

Benthobrookula lamonti Clark, 1961 (figura 2e)

\begin{tabular}{lllllc}
\hline Col. MMUFRPE & Local & Dragagem & $\begin{array}{l}\text { Comprimento } \\
\mathrm{mm}\end{array}$ & $\begin{array}{l}\text { Largura } \\
\mathrm{mm}\end{array}$ & Voltas \\
\hline 4566 & Platô/PE & D-22 & 0,8 & 0,7 & 3,5 \\
\hline
\end{tabular}

Material examinado: 1 exemplar coletado em 06/08/76, dragagem 22; $08^{\circ} 25^{\prime} 01^{\prime}$ 'S, 34 $4^{\circ} 19^{\prime} 01^{\prime \prime}$ W, a 1713 metros de profundidade.

Diagnose: concha microscópica, troquiforme, de espiral não comprimida e fracamente aguda, escuturada, umbilicada e porcelânica. Teleoconcha com 3,5 voltas destrógiras e convexas, ricamente ornamentadas, separadas por uma sutura bem definida. A escultura consiste de numerosas costelas axiais, normalmente elevadas na volta do corpo, cruzadas por quatro cordas espirais na porção média-anterior da última volta, dando a esta um aspecto largamente reticulado, os interespaços são ornados por finas linhas axiais microscópicas de crescimento. A base é estreita e fracamente perfurada, sendo ornada por duas cordas espirais fracas. O umbílico é estreito e pouco profundo, sendo parcialmente recoberto pela região parietal refletida. Abertura circular. A região posterior das costelas axiais da volta do corpo são reforçadas e subsuturalmente existem pequenos nódulos nos ápices destas estruturas. O lábio externo é firmemente recortado pela terminação externa das cordas espirais. A columela é pequena e fracamente curva. A presença de um forte perístoma é quase sempre verificado. Ápice globoso como em Brookula Iredale, 1912.

Ordem Mesogastropoda

Superfamília Rissoidea Adams e Adams, 1854

Família Rissoidae Gray, 1847

Subfamília Singulinae Coan, 1847

Benthonella gaza Dall, 1889 (figura2f)

\begin{tabular}{llllll}
\hline \multirow{2}{*}{ Col. MMUFRPE } & \multirow{2}{*}{ Local } & \multirow{2}{*}{ Dragagem } & $\begin{array}{l}\text { Comprimento } \\
\mathrm{mm}\end{array}$ & $\begin{array}{l}\text { Largura } \\
\mathrm{mm}\end{array}$ & \multirow{2}{*}{ Voltas } \\
\hline \multirow{2}{*}{4567} & \multirow{2}{*}{ Platô/PE } & \multirow{2}{*}{ D-20 } & 1,6 & 0,94 & 3,0 \\
& & & 0,8 & 0,42 & 1,5 \\
\hline
\end{tabular}

Material examinado: 2 exemplares coletados em 06/08/76, dragagem 20; 0740'08' 'S, 34¹1'07' 'W, a 2994 metros de profundidade.

Diagnose: concha pequena, translúcida, de aspecto alongado, espiral elevada e anfractos levemente convexos. Teleoconcha com três voltas destrógiras, podendo chegar a seis em exemplares adultos, separadas por uma sutura canaliculada e profunda. A superfície dos anfractos é inteiramente marcada por linhas axiais de crescimento, muito próximas, dando a falsa idéia de escultura lisa, como em Eulima Risso, 1826. A volta do corpo é extremamente grande, correspondendo a cerca de $50 \%$ do total

Tropical Oceanography, Recife, v. 29, n. 1, p. 59-66, 2001. 


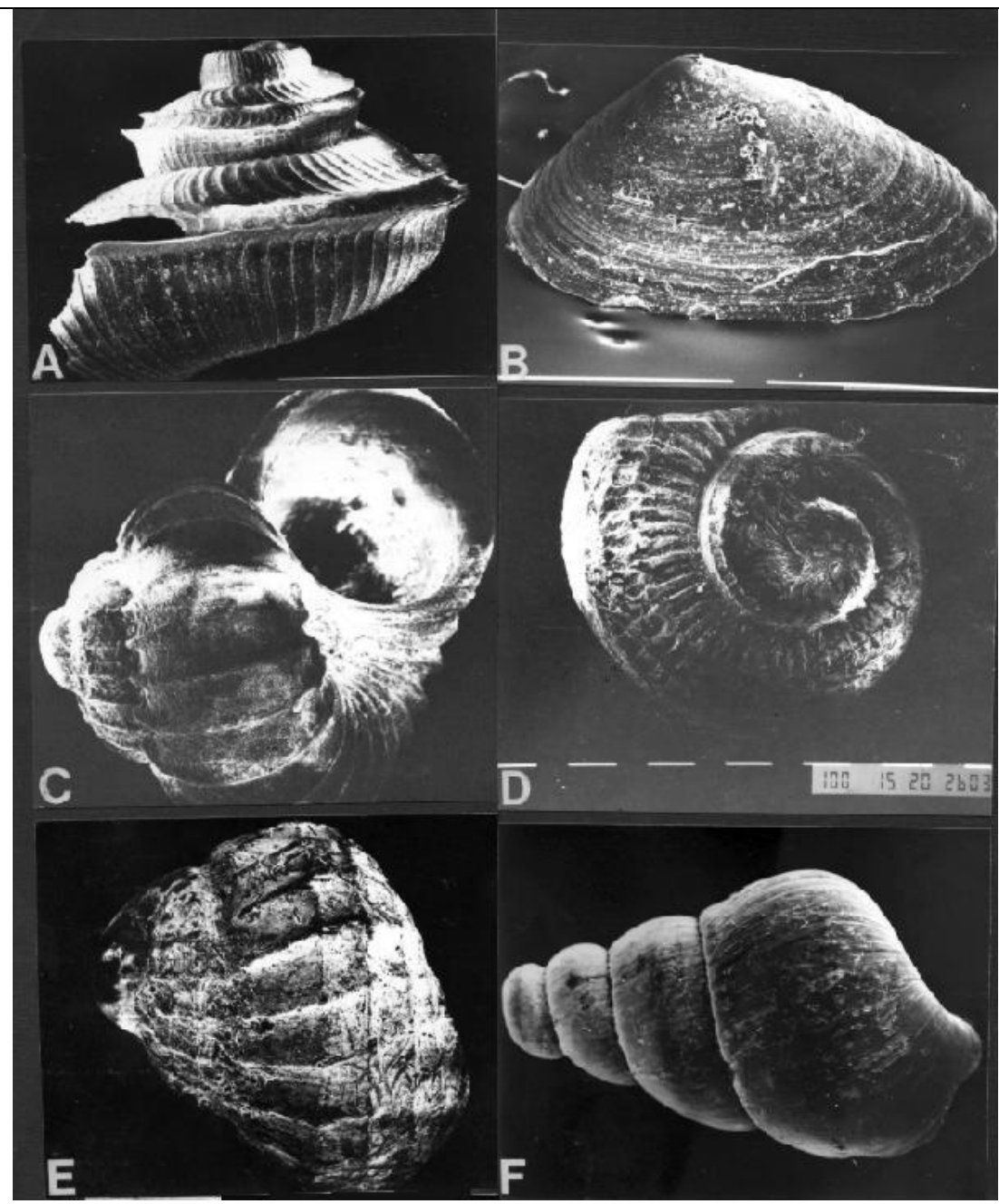

Figura 2 - A- Anatoma aedonia (57X); B- Cocculina aff. rathbuni (60X); C- Brookula conica (99X); D- Benthobroocula powelli (120X); E- Benthobroocula lamonti (19X); F- Benthonella gaza (88X).

\section{CONCLUSÕES}

Confirma-se a presença de Anatoma aedonia (Watson, 1886) após 112 anos do seu primeiro achado na Margem Continental brasileira, assim como, a sua condição endêmica para esta área;

Considera-se ampliado o limite Sul da distribuição geográfica, para o Atlântico Oeste no Hemisfério Sul de Cocculina aff. rathbuni Dall, 1882; Benthobrookula powelli Clark, 1961 e Benthobrookula lamonti Clark, 1961 para 08²5'01' S e 34¹9'01', W, entre 1713 a 2994 metros de profundidade.

Tropical Oceanography, Recife, v. 29, n. 1, p. 59-66, 2001. 


\section{REFERÊNCIAS BIBLIOGRÁFICAS}

ABBOTT, R. T. American Seashells: The Marine Mollusca of the Atlantic and Pacific Coast of North America. 2 ed. New York: Van Nostrand Reinhold, 1974. 633p.

BAYER, F. M. New and usual mollusks collected by r/v John Elliot Pillstur and r/v Gerda in the tropical Western Atlantic. Bull. Mar. Sci., Miami, v. 21, n. 1, p. 111-236, 1971.

CLARK JR, A. H. Abyssal mollusks from the South Atlantic Ocean. Bull. Mus. Comp. Zool. Ottawa, v. 125, n. 12, p. 345-387, 1961.

EKMAN, A. Marine molluscan provinces of Western North America. Proc. Ameri. Philos. Soc., Miami, v. 76, n. 6, p. 921-938, 1953.

RIOS, E. C. Seashells of Brazil. Rio Grande: Fundação da Cidade do Rio Grande; Museu Oceanográfico da Fundação Universidade do Rio Grande, RS. 1994. 368p.

WATSON, R. B. Report on the scientific results of the voyage of the "Challenger" during the years of 1873-1876, Scaphopoda and Gastropoda. v. 15, part 42, London, 1886. 756 p.

Tropical Oceanography, Recife, v. 29, n. 1, p. 59-66, 2001. 